3 Yalcin S, Aydoğan H, Yuce HH, Kucuk A, Karahan MA, Vural M, et al. Effects of sevoflurane and desflurane on oxidative stress during general anesthesia for elective cesarean section. Wien Klin Wochenschr 2013; 125: 467-73.

4 Kalimeris K, Kouni S, Kostopanagiotou G, Nomikos T, Fragopoulou E, Kakisis J, et al. Cognitive function and oxidative stress after carotid endarterectomy: comparison of propofol to sevoflurane anesthesia. J Cardiothorac Vasc Anesth 2013; 27: 1246-52.

Jong-Ling Fuh, Neurological Institute, Taipei Veterans General Hospital, Taipei Taiwan. Email: jffuh@vghtpe.gov.tw; Chih-Wen Yang, Department of Neurology, Taipei Veterans General Hospital, Su-Ao and Yuanshan Branch, and National Yang-Ming University School of Medicine, Taipei, Taiwan

doi: 10.1192/bjp.204.2.163a

\section{Physiotherapists can help implement physical activity programmes in clinical practice}

We read with great interest the editorial by McNamee et al. ${ }^{1}$ The authors made an important call for evidence-based physical activity research and interventions to reduce the physical health disparity seen in people with schizophrenia. Since this an area which is constantly evolving, we wanted to highlight some new evidence that is available that may assist clinicians and researchers to develop evidence-based physical activity interventions.

McNamee et al ${ }^{1}$ report some important barriers to physical activity uptake and maintenance. However, our understanding of the barriers to physical activity participation go beyond negative symptoms, side-effects of medication and social isolation. ${ }^{1}$ Recent review evidence ${ }^{2}$ incorporating 25013 people with schizophrenia provides further indications of specific barriers which should be considered in this population. This comprehensive review ${ }^{2}$ suggests that cardiometabolic comorbidity, lack of knowledge on cardiovascular disease risk factors, lower self-efficacy and other unhealthy lifestyle habits, including smoking, must be carefully considered as barriers when developing physical activity interventions for patients with schizophrenia.

We agree with McNamee et al that there is a high need for theoretically based research on the motivational processes linked to the commencement and continuation of physical activity in patients with schizophrenia. Research has recently started to meet this call. New evidence relying on the self-determination theory ${ }^{3}$ suggests that people with schizophrenia's level of autonomous motivation towards an active lifestyle (which involves the experience of volition and choice), feelings of competence and social relatedness may play an important role in the adoption and maintenance of physical activity.

We also agree with McNamee et al that it is essential that all members of the mental health multidisciplinary team (MDT) should promote and empower people with schizophrenia to engage in physical activity. The International Organization of Physical Therapists in Mental Health (IOPTMH) ${ }^{4}$ recently emphasised that the mental health MDT's approach to the care of patients with schizophrenia should take this into account, at both policy-making and clinical levels. Without this crucial step the physical health of patients with schizophrenia is unlikely to be improved. The IOPTMH therefore endorses the editorial of McNamee et al that active physical health promotion must be routinely included in the care plans of people with schizophrenia and accepted as the responsibility of all healthcare staff. The IOPTMH is committed to supporting future research in this field and believes that physiotherapists are well placed to lead the translation of physical activity in clinical practice, ${ }^{5}$ which McNamee et $a^{1}$ called for. Future research is required and this should, for example, define which strategies mental health physiotherapists should adopt in order to assist persons with schizophrenia in the transition from hospital to community care. ${ }^{4,5}$ Together with McNamee et al, ${ }^{1}$ we are convinced that this is essential in order to ensure that physical activity is successfully used to significantly improve the physical health and health-related quality of life of people with schizophrenia.

1 McNamee L, Mead G, MacGillivray S, Lawrie SM. Schizophrenia, poor physical health and physical activity: evidence-based interventions are required to reduce major health inequalities. Br J Psychiatry 2013; 203: 239-41.

2 Vancampfort D, Knapen J, Probst M, Scheewe T, Remans S, De Hert M. A systematic review of correlates of physical activity in patients with schizophrenia. Acta Psychiatr Scand 2012; 125: 352-62.

3 Vancampfort D, De Hert M, Vansteenkiste M, De Herdt A, Scheewe TW, Soundy $A$, et al. The importance of self-determined motivation towards physical activity in patients with schizophrenia. Psychiatr Res 2013; 210 812-8.

4 Vancampfort D, De Hert M, Skjaerven L, Gyllensten A, Parker A, Mulders N, et al. International Organization of Physical Therapy in Mental Health consensus on physical activity within multidisciplinary rehabilitation programmes for minimising cardio-metabolic risk in patients with schizophrenia. Disabil Rehabil 2012; 34: 1-12.

5 Stubbs B, Soundy A, Probst M, De Hert M, De Herdt A, Vancampfort D. Understanding the role of physiotherapists in schizophrenia: an International perspective from members of the International Organisation of Physical Therapists in Mental Health (IOPTMH). J Ment Health 2013; in press.

Brendon Stubbs, School of Health and Social Care, University of Greenwich, Eltham London, UK; Michel Probst, KU Leuven Department of Rehabilitation Sciences, Leuven, and University Psychiatric Centre KU Leuven, Kortenberg, Belgium; Andy Soundy, Department of Physiotherapy, School of Health and Population Science, University of Birmingham, Birmingham, UK; Anne Parker, Royal Edinburgh Hospital, Morningside, Edinburgh, UK; Amber De Herdt, KU Leuven Department Centre KU Leuven, Kortenberg, Belgium; Alex J. Mitchell, Leicestershire Partnership Centre KU Leuven, Kortenberg, Belgium; Alex J. Mitchell, Leicestershire Partners
Trust, Leicester, UK, and Department of Cancer Studies and Molecular Medicine, University of Leicester, Leicester, UK; Davy Vancampfort, KU Leuven Department of Rehabilitation Sciences, Leuven, and University Psychiatric Centre KU Leuven, Campus Kortenberg, Leuvensesteenweg 517, B-3070 Kortenberg, Belgium. Email: davy.vancampfort@uc-kortenberg.be; on behalf of the International Organization of Physical Therapists in Mental Health

doi: 10.1192/bjp.204.2.164

\title{
Corrections
}

Highlights of this issue. BJP, 204, A3: was written by Sukhwinder S. Shergill. The online version has been corrected post-publication, in deviation from print, and in accordance with this correction.

Skype and narcissistic disturbances: a unique opportunity (letter)? $B J P, 204,79$. In the third paragraph, lines 2 and 6: the surname of the author discussed is Kohut. 